\title{
Effect of Denture Adhesives on Adhesion of Candida albicans to Denture Base Materials: An In Vitro Study
}

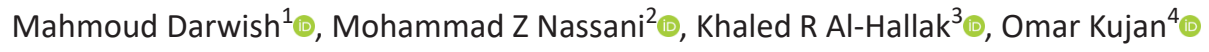

\begin{abstract}
Aim and objective: This study aimed to investigate the adhesion of Candida albicans (CA) to the surface of the denture base using two different types of resins after exposure to denture adhesives (DAs).

Materials and methods: Twenty-five samples of polymethyl methacrylate (PMMA) and 25 samples of urethane dimethacrylate (UDMA) $(10 \mathrm{~mm} \times 10 \mathrm{~mm} \times 2 \mathrm{~mm}$ ) were prepared and allocated to 10 groups (five samples in each group). For each type of denture base materials, four test groups were immersed for 30 days in four commercially available DAs in addition to water as control group. Specimens were then in vitro evaluated for $C A$ adhesion using light microscopy under $\times 1,000$ magnification.

Results: The results showed that the mean number of CA per specimen in the adhesive-exposed groups was higher than that in the control group for both UDMA and PMMA resins. However, this difference was not statistically significant. No association between the type of denture base material and Candida count was identified following immersion in different types of DA and distilled water $(p>0.05)$. Candida count was not associated with the type of DA when UDMA specimens were compared $(p>0.05)$. PMMA resin specimens that were immersed in Corega cream showed significantly higher counts of Candida compared to control specimens that were immersed in distilled water ( $p<0.05$ ).

Conclusion: The study found no association between the type of denture base materials and CA adhesion. No clear impact was identified for the type of DA on CA adhesion to acrylic denture bases.

Clinical significance: Using DAs would likely not increase the incidence of denture stomatitis in completely edentulous patients.

Keywords: Candida adhesion, Dentures adhesives, Denture bases.

The Journal of Contemporary Dental Practice (2021): 10.5005/jp-journals-10024-3209
\end{abstract}

\section{INTRODUCTION}

Candida albicans (CA) is considered one of the most opportunistic microorganisms that can cause mucosal fungal infections among human beings. It is commensal in the oral cavity of $45-65 \%$ of healthy individuals and may increase to $60-100 \%$ in denture wearers. ${ }^{1-3}$ Presence of dentures in the oral cavity is one of the local factors that may trigger Candida infection. ${ }^{4}$ The available evidence indicates that Candida can adhere to acrylic resin dentures. Candida adhesion is the first step that may lead to progression of the infectious process and that may essentially result in varying degrees of denture stomatitis of the adjacent mucosa. ${ }^{5-7}$ Candida adheres directly or by a layer of denture plaque to denture bases. Without this adherence, microorganisms would be removed from the oral cavity when saliva or food is being swallowed. ${ }^{8,9}$ Many factors related to acrylic resin denture bases such as chemical composition, surface charge, surface free energy, hydrophobicity, as well as surface roughness, have been implicated as major factors in Candida adhesion. ${ }^{10-13}$ Denture adhesives (DAs) are present in various formulations such as powders, pastes, or cream for soluble adhesives and strips or cushions for insoluble adhesives. A large number of denture wearers regularly use DAs as an aid to improve denture retention, stability, and function. ${ }^{14}$ DAs should possess a number of properties including easy application and removal by the patient, appropriate flavor and consistency, does not alter or deteriorate denture material, and does not enhance bacterial and fungal growth. 15,16

Many researchers have examined the interactions between DAs and oral microbiota. However, the results were conflicting and debatable. Early in 1971, an in vitro study done by Stafford and Russell showed that some DAs supported CA growth, inducing hyphal formation. ${ }^{17}$ Another study suggested that
${ }^{1}$ Department of Prosthetic Dental Sciences, Vision College of Dentistry and Nursing, Riyadh, Saudi Arabia; Prosthodontics Department, Faculty of Dentistry, Suez Canal University, Ismailia, Egypt

${ }^{2}$ Department of Restorative and Prosthetic Dental Sciences, College of Dentistry, Dar Al Uloom University, Riyadh, Saudi Arabia

${ }^{3}$ Oral Bioengineering Centre, School of Dentistry, Queen Mary University of London, London, United Kingdom

${ }^{4}$ Oral Diagnostic and Surgical Sciences, UWA Dental School, University of Western Australia, Nedlands, Western Australia, Australia

Corresponding Author: Mohammad Z Nassani, Department of Restorative and Prosthetic Dental Sciences, College of Dentistry, Dar Al Uloom University, Riyadh, Saudi Arabia, Phone: +966 11 4949107, e-mail: mznassani@dau.edu.sa

How to cite this article: Darwish M, Nassani MZ, Al-Hallak KR et al. Effect of Denture Adhesives on Adhesion of Candida albicans to Denture Base Materials: An In Vitro Study. J Contemp Dent Pract 2021;22(11):1257-1261.

Source of support: Nil

Conflict of interest: None

DAs possess antifungal activity. ${ }^{18}$ Furthermore, two in vivo studies indicated that DAs did not significantly alter the oral microbiota over a 14-day trial period. ${ }^{1,19}$ Sampaio-Maia et al. concluded from their in vitro study that some DAs showed microbial contaminations and some had a significant inhibitory effect on CA growth. ${ }^{20}$ The continuous usage of DAs could compromise surface properties of denture base resins enhancing microorganism adhesion. Moreover, denture surface can act as a microorganism reservoir facilitating denture user reinfection. ${ }^{21}$ However, the effect 
of DAs on adhesion of CA to the surface of denture base materials is not yet evident. This in vitro study aimed to evaluate and compare the adhesion of CA to the surface of polymethyl methacrylate (PMMA) and urethane dimethacrylate (UDMA) denture base resins after application of four commercially available DAs.

\section{Materials and Methods}

This study was conducted at Vision College of Dentistry and Nursing, Riyadh, KSA. The study design is illustrated in Flowchart 1. All materials used in the study were outlined in Table 1.

Flowchart 1: Study design

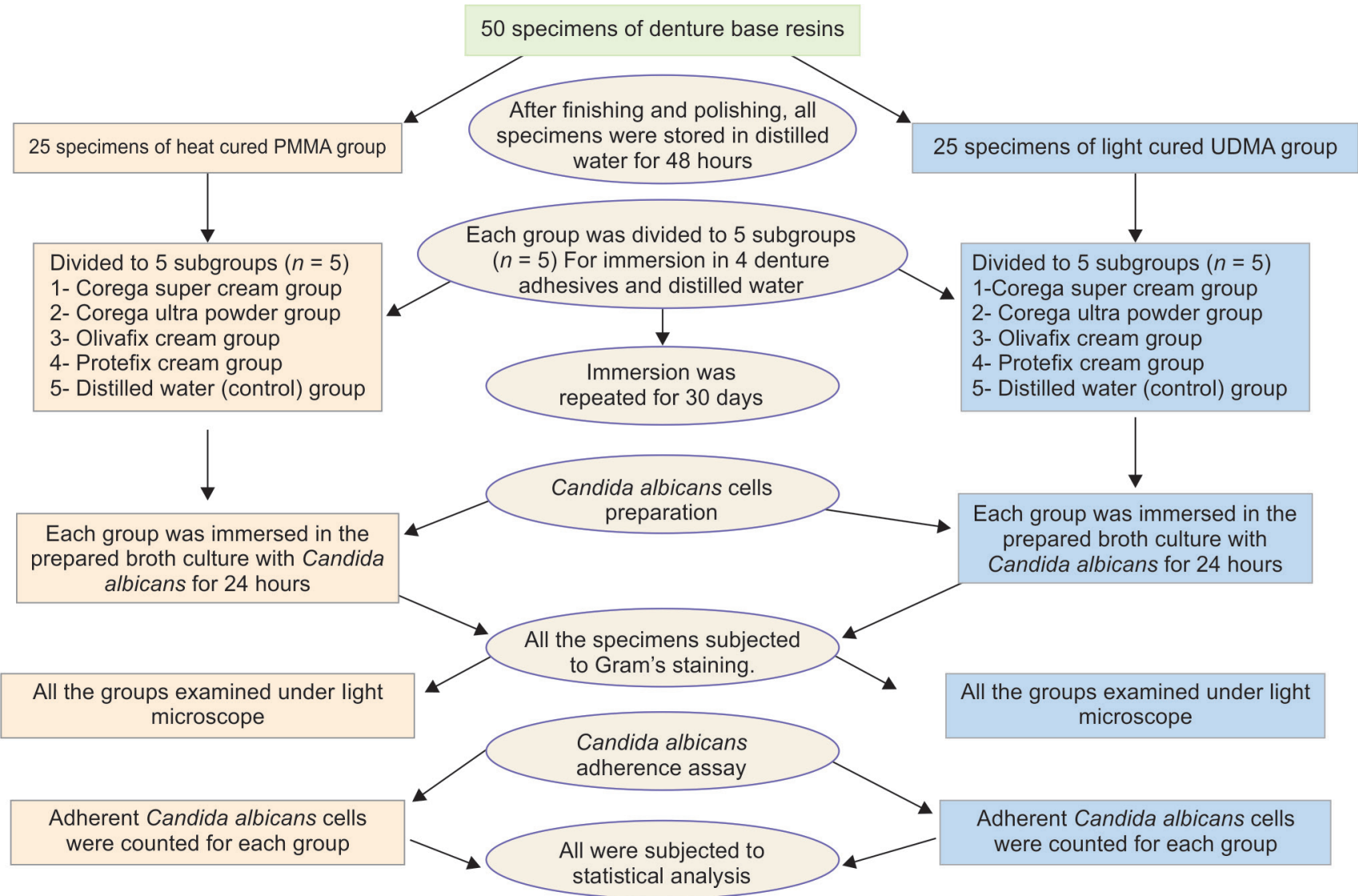

Table 1: Chemicals and compounds utilized in the experiments

\begin{tabular}{|c|c|c|c|c|}
\hline Product name & Material type & Composition & Manufacturer & Batch no. \\
\hline Eclipse & $\begin{array}{l}\text { Denture base } \\
\text { resin }\end{array}$ & $\begin{array}{l}\text { Matrix: UDMA } \\
\text { Filler: silica, PMMA beads }\end{array}$ & Dentsply, New York, USA & 120612 \\
\hline Eco-cryl hot & $\begin{array}{l}\text { Denture base } \\
\text { resin }\end{array}$ & $\begin{array}{l}\text { Powder: methyl methacrylate-copolymer } \\
\text { Liquid: methyl methacrylate-monomer }\end{array}$ & Protechno, Girona, Spain & $12-26964$ \\
\hline $\begin{array}{l}\text { Corega super } \\
\text { cream }\end{array}$ & Denture adhesive & $\begin{array}{l}\text { Poly(methyl vinyl ether/maleic acid) } \\
\text { sodium-calcium mixed partial salt, } \\
\text { petrolatum, cellulose gum, paraffinum } \\
\text { liquidum }\end{array}$ & $\begin{array}{l}\text { Stafford-Miller } \\
\text { (Dungarvan, Ireland) }\end{array}$ & V12353A \\
\hline $\begin{array}{l}\text { Corega ultra } \\
\text { powder }\end{array}$ & Denture adhesive & $\begin{array}{l}\text { Poly(methyl vinyl ether/maleic acid) } \\
\text { sodium-calcium mixed partial salt, cellulose } \\
\text { gum, flavor }\end{array}$ & $\begin{array}{l}\text { Stafford-Miller } \\
\text { (Dungarvan, Ireland) }\end{array}$ & N13032 \\
\hline Olivafix cream & Denture adhesive & $\begin{array}{l}\text { Cellulose gum, Olea Europaea (Olive oil), } \\
\text { calcium-sodium, PVM/MA copolymer, } \\
\text { hydrogenated soybean oil, trihydroxystearin, } \\
\text { silica, menthol, lecithin, Citrus limonum, } \\
\text { menthyl lactate }\end{array}$ & $\begin{array}{l}\text { bonyf AG } \\
\text { (Liechtenstein, EU), Swiss }\end{array}$ & $41-27$ \\
\hline Protefix cream & Denture adhesive & $\begin{array}{l}\text { Poly(methyl vinyl ether/maleic acid) } \\
\text { sodium-calcium partial salt, carboxymethyl } \\
\text { cellulose, paraffin, Vaseline, silica, menthol, } \\
\text { azorubin, p-hydroxybenzoic acid } \\
\text { methyl ester }\end{array}$ & $\begin{array}{l}\text { Queisser Pharma } \\
\text { (Flensburg, Germany) }\end{array}$ & 088072 \\
\hline
\end{tabular}




\section{Sample Fabrication}

Fifty samples $(10 \mathrm{~mm} \times 10 \mathrm{~mm} \times 2 \mathrm{~mm})$ of denture base materials were prepared: 25 PMMA specimens and 25 UDMA specimens. Conventional flasking procedures were used to prepare PMMA samples, and the acrylic resin was processed following the short curing cycle in a thermostatically controlled water bath following the instructions of the manufacturer. For UDMA samples, a silicon material (Deguform plus, DeguDent GmbH, Hanau, Germany) was used to prepare rubber mold by investing wax into it. A separating medium (Al-Cote, Dentsply, USA) was used to line the rubber mold. After that, the prepacked resin was placed into the rubber mold by finger pressure. For UDMA specimens, their exposed surface received an air barrier coating (Eclipse, Air Barrier Coating, Dentsply, USA), and then, it was polymerized for 10 minutes in a curing unit (Eclipse, Dentsply, USA). The fabricated samples were checked for the absence of porosities or voids. Finishing disks and stones were used to prepare the study specimens to the desired dimensions. One side of the specimens was finished to a smooth surface using sandpapers with fine grits $(280,360$, and 400 -Middle East Factory, Riyadh, KSA) followed by polishing. To eliminate the residual monomer, test specimens were kept for 48 hours in distilled water at $37^{\circ} \mathrm{C}$. All specimens were prepared by the same operator. Afterward, the samples were subdivided into five groups: one control group immersed in distilled water and four test sets that were immersed in four different DAs.

\section{Denture Adhesive Preparation}

The DAs used were prepared as recommended by the previous studies $^{15,22}$ in a solution to be consistent with the oral cavity environments. To prepare the DAs, $1 \mathrm{~g}$ from each type (Corega ultra powder, protefix cream, Corega super cream, and Olivafix cream) was mixed with $10 \mathrm{~mL}$ distilled water in plastic containers. Four test groups from both types of resin specimens were immersed in the prepared DAs and the control group specimens were immersed in $10 \mathrm{~mL}$ distilled water. The specimens were immersed for 16 hours/day, and all containers were incubated at $37^{\circ} \mathrm{C}$. Then, the specimens were taken out from DAs and rinsed under running water for 10 seconds. Next, the samples from each group were put in distilled water for 8 hours at normal temperature and pressure. This procedure was repeated for 30 days, whereas the adhesives were replaced and prepared daily.

\section{Yeast Cell Preparation}

CA strain ATCC 24433 was obtained as a stock culture from the microbiology laboratory at Vision Colleges of Dentistry and Nursing in Riyadh. This strain was subcultured from a thawed suspension of ATCC 24433 strains as follows: thaw the fungal strain in a water bath at $25-30^{\circ} \mathrm{C}$. Then immediately, wipe down the ampoule with ethanol (70\%) and aseptically transfer $100 \mu \mathrm{L}$ of the content onto fresh yeast Peptone Dextrose Agar media (Hardy Diagnostic, CulGenex $\left.{ }^{\mathrm{TM}}\right)$. After 48 -hour incubation at $37^{\circ} \mathrm{C}$, the cells were maintained at $4^{\circ} \mathrm{C}$ until further usage. Prior to use in cell adhesion, CA cells were transferred into $10 \mathrm{~mL}$ of Sabouraud's broth (Hardy Diagnostic, CulGenex ${ }^{\mathrm{TM}}$ ) using a sterilized cotton swap and incubated at $37 \pm 2^{\circ} \mathrm{C}$ overnight. Then, $10 \mathrm{~mL}$ of the overnight broth culture at 0.5 McFarland Equivalence to $10^{7}$ colony-forming units (CFU/mL) was added to $90 \mathrm{~mL}$ of Sabouraud's broth and further incubated at $37^{\circ} \mathrm{C}$ for 24 hours to attain a stationary phase.

\section{Adherence Assay}

All denture base specimens were sterilized in sterile Petri dishes. The specimens of each group were then immersed in $10 \mathrm{~mL}$ of the 24-hour broth culture with CA (ATCC 24433) at 0.5 McFarland scale overnight at $37^{\circ} \mathrm{C}$. The specimens were removed using sterile forceps and rinsed gently twice for 15 seconds with phosphatebuffered saline (0.15 M,PH 7.2).

The microbial biofilm on the specimens was fixed using absolute methyl alcohol for 1 minute, and the specimens were then plotted on paper towel and stained using Gram's staining technique. ${ }^{23}$ All samples were washed in phosphate-buffered saline solution for 30 seconds by gentle agitation using bench top shaker (50 rpm) and examined by light microscopy (Leica DM 300 , Microsystems, Switzerland) under $\times 1,000$ magnification. The adherent Candida cells in five fields of view $\left(0.25 \mathrm{~mm}^{2}\right.$ per field) were counted, and the results were expressed as yeast cells $/ \mathrm{mm}^{2}$ of each of the denture base samples.

\section{Statistical Analysis}

CA adhesion readings were calculated and tabulated. Statistical Package for Social Science (SPSS) (IBM Corp., Armonk, New York, USA) was used for data analysis. The Shapiro-Wilk test was used to evaluate the distribution of the collected data and indicated normal distribution. The test groups illustrated homogeneity in the variance according to Levene's statistical test. In order to identify any statistically significant differences among study groups, the $t$-test for independent observations and the one-way analysis of variance (ANOVA) followed by post hoc Tukey's comparison tests were used. The level of significance was set at $p<0.05$.

\section{Results}

Table 2 shows the mean and standard deviation of CA per specimen of the adhesive-exposed groups in addition to the distilled water group for both UDMA and PMMA resins. The results showed that the mean number of CA per specimen in the adhesive-exposed groups

Table 2: Candida count (mean value \pm SD) attached to denture base materials after immersion in DAs and distilled water $p$ s of $t$-test for independent observations

\begin{tabular}{|c|c|c|c|c|c|c|}
\hline \multirow[b]{2}{*}{ Adhesive type } & \multirow{2}{*}{$\begin{array}{c}\text { UDMA resin } \\
\text { Candida count } \\
\text { Mean } \pm S D\end{array}$} & \multirow{2}{*}{$\begin{array}{c}\text { PMMA resin } \\
\text { Candida count } \\
\text { Mean } \pm S D\end{array}$} & \multirow[b]{2}{*}{ Mean difference } & \multicolumn{2}{|c|}{$95 \% \mathrm{Cl}$ of the difference } & \multirow[b]{2}{*}{$p$} \\
\hline & & & & Lower & Upper & \\
\hline Corega cream & $47.36 \pm 13.59$ & $62.00 \pm 21.90$ & -14.64 & -41.22 & 11.94 & 0.240 \\
\hline Corega powder & $47.08 \pm 10.28$ & $42.44 \pm 6.29$ & 4.64 & -7.79 & 17.07 & 0.414 \\
\hline Olivafix cream & $46.20 \pm 7.61$ & $36.52 \pm 16.00$ & 9.68 & -8.37 & 27.73 & 0.251 \\
\hline Protefix cream & $44.64 \pm 10.96$ & $42.40 \pm 11.25$ & 2.24 & -13.95 & 18.43 & 0.758 \\
\hline Control (distilled water) & $37.84 \pm 5.64$ & $33.28 \pm 3.32$ & 4.56 & -2.19 & 11.31 & 0.158 \\
\hline
\end{tabular}

$\mathrm{SD}$, standard deviation; $\mathrm{Cl}$, confidence interval of the difference; UDMA, urethane dimethacrylate; PMMA, polymethyl methacrylate 
$(47.36 \pm 13.59,47.08 \pm 10.28,46.20 \pm 7.61$, and $44.64 \pm 10.96$ for UDMA groups) and ( $62.00 \pm 21.90,42.44 \pm 6.29,36.52 \pm 16.00$, and $42.40 \pm 11.25$ for PMMA) was higher than that in the nonexposed group (control group: $37.84 \pm 5.64$ and $33.28 \pm 3.32$ ) for both UDMA and PMMA resins, respectively.

Table 2 reveals no association between the type of denture base material and Candida count following immersion in different types of DA and distilled water $(p>0.05)$. On the contrary, the one-way ANOVA test did not identify any association between the type of DA and Candida count when UDMA specimens were compared $(p>0.05)$. The one-way ANOVA test followed by post hoc Tukey's comparison tests indicated that PMMA resin specimens that were immersed in Corega cream showed significantly higher counts (62.00 \pm 21.90$)$ of Candida compared to control specimens $(33.28 \pm 3.32)$ that were immersed in distilled water $(p<0.05)$ (Table 3).

Table 3: Mean difference, 95\% confidence interval for mean and PS for the Tukey's honestly significant difference (HSD) test to examine the impact of the type of DA on Candida count with PMMA resin specimens

\begin{tabular}{|c|c|c|c|c|c|}
\hline & \multirow[b]{2}{*}{ Adhesive type } & \multirow{2}{*}{$\begin{array}{c}\text { Mean } \\
\text { difference }\end{array}$} & \multicolumn{2}{|c|}{$95 \% \mathrm{Cl}$ of the difference } & \multirow[b]{2}{*}{$p$ value } \\
\hline & & & Lower & Upper & \\
\hline \multirow{4}{*}{$\begin{array}{l}\text { Corega } \\
\text { cream }\end{array}$} & Corega powder & 19.56 & -6.01 & 45.13 & 0.189 \\
\hline & Olivafix cream & 25.48 & -0.09 & 51.05 & 0.051 \\
\hline & Protefix cream & 19.60 & -5.97 & 45.17 & 0.188 \\
\hline & Distilled water & 28.72 & 3.15 & 54.29 & $0.023^{*}$ \\
\hline
\end{tabular}

*Significant difference at $p<0.05$

\section{Discussion}

Despite the wide use of dental implants in supporting and retaining complete dentures, DAs still have their viable role as an aid for the retention of conventional complete dentures among a considerable proportion of completely edentulous patients. However, the extended use of DAs may be associated with a number of biological and clinical complications. In this study, we examined the impact of four DAs on the adhesion of CA to the surface of the denture base using two different types of resins. Based on the findings, the extent to which DAs may affect the adhesion of CA to denture surface is not yet clear. While mostly the results of this investigation support the tested null hypothesis of no impact for DAs on the adhesion of CA to the surface of the denture base, the use of Corega cream with PMMA resin comes as an exception.

In the present paper, most of the tested DAs produced an insignificant increase in the adhesion of CA compared to the control groups for both types of used denture bases. It appears that most of the used DAs did not deteriorate or compromise the surface properties of denture bases. This finding could be due to the similarity in the chemical composition between the used DAs and acrylic denture base resins. This finding is in line with the results of Darwish and Nassani ${ }^{24}$ who assessed the impact of different DAs on the surface roughness of denture base and found that most of the tested DAs did not make a significant difference to the surface roughness of denture base resin after 30 days of continues application. Surface roughness is an important factor that may enhance microbial retention ${ }^{25-27}$ because of the increased surface area available for colonization by increasing the microorganism/ material interface. ${ }^{28,29}$ However, only Corega Super cream-exposed group of PMMA specimens demonstrated a significant increase in the number of CA adhesion compared to control specimens that were immersed in distilled water. This finding may be related to changes that may occur to surface characteristics of PMMA specimens in terms of increase in surface roughness, if we consider the results of Darwish and Nassani study ${ }^{24}$ that the only DA that produced a detectable increase in surface roughness of PMMA and UDMA specimens was Corega Super cream DA.

Despite the probability of an increase in surface roughness in UDMA specimens, due to the effect of Corega Super cream as was found by Darwish and Nassani ${ }^{24}$ the increase in the CA adhesion was nonsignificant if compared with other test UDMA groups. This result can be explained by the presence of other factors rather than surface roughness, like wettability or surface free energy that may affect fungi adhesion. ${ }^{30}$ Exposure of UDMA specimens to DAs may render the surface to be more hydrophobic, and, hence reduce the effect of surface roughness, so less cell adherence is expected. In previous studies, a direct relationship between surface free energy, and $C A$ adhesion was reported. ${ }^{4,12}$

In the present investigation, there were no statistically significant differences in the CA counts between PMMA groups and UDMA groups, regardless if it was exposed to DAs or not (control group). This finding is in contrast with the result of a study performed by Koch et al. who found a significantly higher Candida count with UDMA (Eclipse) denture bases when compared with other heat-cured PMMA denture base material after exposure to thermal cycling to simulate an artificial aging process. ${ }^{13}$ This contrast could be due to the use of different PMMA materials, in addition to different treatments done to the specimens. In Koch et al. study, ${ }^{13}$ the specimens were subjected to thermal cycling while in this study, the specimens were exposed to DAs. These differences in the treatment may induce changes in surface properties of denture base resins that may be critical for CA adhesion.

During the interpretation of the results of this study, the following limitations should be considered; the surfaces of the denture base utilized in the present investigation are not mimicking the fitting surfaces of a denture in vivo. As well, the concentration of DAs used in this study does not represent the concentration when used in vivo because of the effect of saliva dilution in the oral cavity. This concentration, on the contrary, may indicate a longer application period. Also, the simulation of the intraoral temperature and $\mathrm{pH}$ variations, as well as mechanical loads during masticatory function, considered the restrictions of this study. Lastly, the formation of single species CA under semistatic incubation conditions in a thermally controlled device does not perfectly correspond to the oral cavity due to the lack of dynamic incubation conditions.

\section{Conclusion}

Within the limitations of this study, it may be concluded that there is no association between the type of denture base materials and CA adhesion. No clear impact can be identified for the type of DA on CA adhesion to denture bases.

\section{Authors Contributions}

The research concept and design were done by all the authors Mahmoud Darwish, Mohammad Z Nassani, Khaled R Al-Hallak, and Omar Kujan. The collection and/or assembly of data was done by Mahmoud Darwish and Khaled R Al-Hallak. Data analysis 
and interpretation were carried out by Mahmoud Darwish and Mohammad Z Nassani. The manuscript was written by Mahmoud Darwish and then critically reviewed by the rest of the authors. All authors approved the final manuscript.

\section{Acknowledgment}

Authors would like to thank Vision College of Dentistry and Nursing and the Deanship of Graduate Studies and Scientific Research at Dar Al Uloom University for their support in the publication of this research.

\section{ORCID}

Mahmoud Darwish (1) http://orcid.org/0000-0003-3784-9633 Mohammad Z Nassani 『 http://orcid.org/0000-0003-0927-895X Khaled R Al-Hallak @ http://orcid.org/0000-0002-9756-7147 Omar Kujan (1) http://orcid.org/0000-0002-5951-8280

\section{References}

1. Oliveira MC, Oliveira VM, Vieira AC, et al. In vivo assessment of the effect of an adhesive for complete dentures on colonization of Candida species. Gerodontology 2010;27(4):303-307. DOI: 10.1111/j.1741-2358.2009.00345.x.

2. Richardson M, Lass-Florl C. Changing epidemiology of systemic fungal infections. Clin Microbiol Infect 2008;14(Suppl 4):5-24. DOI: 10.1111/j.1469-0691.2008.01978.x.

3. Morschhauser J. Regulation of multidrug resistance in pathogenic fungi. Fungal Genet Biol 2010;47(2):94-106. DOI: 10.1016/ j.fgb.2009.08.002.

4. Al-Dwairi ZN, Al-Quran FA, Al-Omari OY. The effect of antifungal agents on surface properties of poly (methyl methacrylate) and its relation to adherence of Candida albicans. J Prosthodont Res 2012;56(4):272-280. DOI: 10.1016/j.jpor.2012.02.006.

5. Cannon RD, Chaffin WL. Oral colonization by Candida albicans. Crit Rev Oral Biol Med 1999;10(3):359-383. DOI: 10.1177/ 10454411990100030701.

6. Chandra J, Mukherjee PK, Leidich SD, et al. Antifungal resistance of candidal biofilms formed on denture acrylic in vitro. J Dent Res 2001;80(3):903-908. DOI: 10.1177/00220345010800031101.

7. Ramage $G$, Tomsett $K$, Wickes BL, et al. Denture stomatitis: a role for Candida biofilms. Oral Surg Oral Med Oral Pathol Oral Radiol Endod 2004;98(1):53-59. DOI: 10.1016/j.tripleo.2003.04.002.

8. Branting C, Sund ML, Linder LE. The influence of Streptococcus mutans on adhesion of Candida albicans to acrylic surfaces in vitro. Arch Oral Biol 1989;34(5):347-353. DOI: 10.1016/0003-9969(89)90108-8.

9. Park SA, Blissett R, Susarla SM, et al. Candida albicans adherence to surface-modified denture resin surfaces. J Prosthodont 2008;17(5):365-369. DOI: 10.1111/j.1532-849X.2007.00292.x.

10. Bridgett MJ, Davies MC, Denyer SP, et al. In vitro assessment of bacterial adhesion to Hydromer-coated cerebrospinal fluid shunts. Biomaterials 1993;14(3):184-188. DOI: 10.1016/0142-9612(93)90021-s.

11. Verheyen CC, Dhert WJ, de Blieck-Hogervorst JM, et al. Adherence to a metal, polymer and composite by Staphylococcus aureus and Staphylococcus epidermidis. Biomaterials 1993;14(5):383-391. DOI: 10.1016/0142-9612(93)90059-b.

12. Minagi S, Miyake $Y$, Inagaki $K$, et al. Hydrophobic interaction in Candida albicans and Candida tropicalis adherence to various denture base resin materials. Infect Immun 1985;47(1):11-14. DOI: 10.1128/ iai.47.1.11-14.1985.

13. Koch C1, Bürgers R, Hahnel S. Candida albicans adherence and proliferation on the surface of denture base materials. Gerodontology 2013;30:309-313. DOI: 10.1111/ger.12056.

14. Kalra P, Nadiger R, Shah FK. An investigation into the effect of denture adhesives on incisal bite force of complete denture wearers using pressure transducers- a clinical study. J Adv Prosthodont 2012;4(2):97-102. DOI: 10.4047/jap.2012.4.2.97.

15. Zhao K, Cheng XR, Chao YL, et al. Laboratory evaluation of a new denture adhesive. Dent Mater 2004;20(5):419-424. DOI: 10.1016/ j.dental.2002.12.001.

16. Adisman IK. The use of denture adhesives as an aid to denture treatment. J Prosthet Dent 1989;62(6):711-715. DOI: 10.1016/ 0022-3913(89)90598-2.

17. Stafford GD, Russell C. Efficiency of denture adhesives and their possible influence on oral microorganisms. J Dent Res 1971;50(4): 832-836. DOI: 10.1177/00220345710500040701.

18. Makihira S, Nikawa H, Satonobu SV, et al. Growth of Candida species on commercial denture adhesives in vitro. Int J Prosthodont 2001;14(1):48-52. PMID: 11842904.

19. Kim E, Driscoll CF, Minah GE. The effect of a denture adhesive on the colonization of Candida species in vivo. J Prosthodont 2003;12(3): 187-191. DOI: 0.1016/S1059-941X(03)00050-0.

20. Sampaio-Maia B, Figueiral MH, Sousa-Rodrigues $P$, et al. The effect of denture adhesives on Candida albicans growth in vitro. Gerodontology 2012;29(2):348-356. DOI: 10.1111/j.1741-2358. 2011.00478.x.

21. Arendorf TM, Walker DM. Denture stomatitis: a review. J Oral Rehabil 1987;14(3):217-227. DOI: 10.1111/j.1365-2842.1987.tb00713.x.

22. Love WB, Biswas S. Denture adhesives--pH and buffering capacity. J Prosthet Dent 1991;66(3):356-360. DOI: 10.1016/0022-3913(91)90263-v.

23. Raut JS, Ravikumar BS, Nitin MC, et al. Phenylpropanoids of plant origin as inhibitors of biofilm formation by Candida albicans. J Microbiol Biotechnol 2014;24(9):1216-1225. DOI: 10.4014/jmb.1402.02056.

24. Darwish M, Nassani MZ. Evaluation of the effect of denture adhesives on surface roughness of two chemically different denture base resins. Eur J Dent 2016;10(3):321-326. DOI: 10.4103/1305-7456.184155.

25. Verran J, Maryan CJ. Retention of Candida albicans on acrylic resin and silicone of different surface topography. J Prosthet Dent 1997;77(5):535-539. DOI: 10.1016/s0022-3913(97)70148-3.

26. Radford DR, Sweet SP, Challacombe SJ, et al. Adhesion of Candida albicans to denture-base materials with different surface finishes. J Dent 1998;26(7):577-583. DOI: 10.1016/s03005712(97)00034-1.

27. Taylor R, Maryan C, Verran J. Retention of oral microorganisms on cobalt-chromium alloy and dental acrylic resin with different surface finishes. J Prosthet Dent 1998;80(5):592-597. DOI: 10.1016/s00223913(98)70037-x.

28. Radford DR, Challacombe SJ, Walter JD. Denture plaque and adherence of Candida albicans to denture-base materials in vivo and in vitro. Crit Rev Oral Biol Med 1999;10(1):99-116. DOI: 10.1177/10454411990100010501.

29. Whitehead KA, Verran J. The effect of surface topography on the retention of microorganisms. Food Bioprod Process 2006;84(4): 253-259. DOI: 10.1205/fbp06035.

30. Al-Bakri IA, Harty D, Al-Omari WM, et al. Surface characteristics and microbial adherence ability of modified polymethylmethacrylate by fluoridated glass fillers. Aust Dent J 2014;59(4):482-489. DOI: 10.1111/ adj.12218. 